\title{
An Optimized Model for Energy Efficiency on Cloud System using PSO \& CUCKOO Search Algorithm
}

\author{
Shanky Goyal, Shashi Bhushan
}

\begin{abstract}
Cloud computing is one of the growing technologies, these days. Cloud computing is a paradigm that is surrounded by multiple resources, which helps in resource utilization. Infrastructure as a Service (IaaS), Platform as a Service (PaaS) and Software as a Service (Saas) are named as services of cloud computing. In the IaaS models, users can rent infrastructure of the data center as a service. Some of the examples of IAAS are Google Compute Engine (GCE) and Amazon Web Service (AWS). In the PaaS models, users can take services like operating system and database. Some of the examples of PAAS are Microsoft Azure and Google App Engine. In the SaaS models, users can access and install application software and databases via Internet. Examples of SAAS are Citrix GoToMeeting and Google Docs. In this paper algorithms named as PSO and CSA are discussed The objective of optimization for energy consumption on cloud has also been discussed in the paper. Along with the optimization techniques, the detailed literature reviews have been presented. To achieve the proposed work, CloudSim simulators and standard programming languages have been used. The performance of the proposed work will be analyzed by using the various performance parameters such as response time, energy efficiency and execution time.
\end{abstract}

Keywords: Cloud Computing, Load balancing, Energy efficiency, Data center, CSA, PSO.

\section{INTRODUCTION}

From early concepts cloud computing has gained lot popularity these days. Many big organizations, business enterprises etc are taking the advantages of cloud services and storing their data over cloud. The most used definition of cloud is given by NIST which states that "Cloud computing is the procedure that permits suitable resources, agreeing as per the requirements of the user on condition to access the network to various computing resources which can be networks, servers, storage, applications and services that can be apportioned and free speedily with least controlling work." In cloud computing, there are four deployment models, five characteristics and three services. Cloud computing in recent time is getting over every ones nervous and it is not possible to ignore its advantages. Advantages of cloud may include e-mail, companies to outsource data, folders and many other requests through virtual platforms through the medium of servers which are associated among them and which can be retrieved anywhere and at any time. The only thing for

Revised Manuscript Received on July 02, 2019.

Shanky Goyal, Research Scholar, computer Science Department, IKGPTU, Jalandhar, Assistant Professor, IT Department, CEC, Landran, Punjab, India India

Shashi Bhushan, Professor, IT deprtment, CEC, Landran, Punjab, accessing the cloud services is to have internet connection. Cloud computing has bring a lot for IT department apart from global and internal organization of the company. Cloud computing has given a lot for back up of data, new tools and perspectives are uplifted by cloud computing for evolution in comp anies. The origin of cloud computing have started far before when flowcharts and presentations were used for presenting servers infrastructure of the Internet. For storage purpose cloud has done a lot work and almost every company these days is using this advantage of cloud. The data can be accessed easily over the internet.



Fig. 1 Cloud computing

\section{ClOUd COMPUTING FRAMEWORK}

\section{A. Architecture of cloud computing}

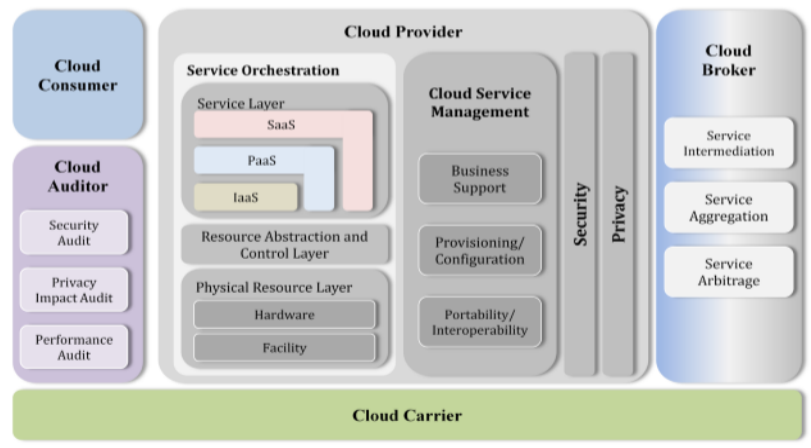

Fig. 2 Cloud computing architecture

The architecture of cloud computing classifies the main artists of cloud computing, their actions and roles that they perform in computing environment. The below given diagram represents the generic high-level architecture with uses, requirements, characteristics and standards 
of cloud computing.

As shown in Fig. 2, the NIST cloud computing mention the designing of cloud computing with five major actors which are cloud provider, cloud broker, cloud consumer, cloud auditor and cloud carrier. Each actor act individually which take part in various tasks of cloud computing.

\section{B. Components of cloud computing}

Table 1. Lists of actors demarcated in cloud computing architecture.

\begin{tabular}{|l|l|}
\hline Actor & Definition \\
\hline $\begin{array}{l}\text { Cloud } \\
\text { Provider }\end{array}$ & $\begin{array}{l}\text { It can be an individual or company which } \\
\text { will be answerable for creation of } \\
\text { services accessible to involved parties. }\end{array}$ \\
\hline $\begin{array}{l}\text { Cloud } \\
\text { Consumer }\end{array}$ & $\begin{array}{l}\text { It can be an individual or company which } \\
\text { help in keeping business relationships and } \\
\text { take the services from cloud providers. }\end{array}$ \\
\hline $\begin{array}{l}\text { Cloud } \\
\text { Auditor }\end{array}$ & $\begin{array}{l}\text { One that keep the proper records of cloud } \\
\text { services, information system operations, } \\
\text { performance and security used by cloud } \\
\text { computing. }\end{array}$ \\
\hline $\begin{array}{l}\text { Cloud } \\
\text { Carrier }\end{array}$ & $\begin{array}{l}\text { A middle which help in providing } \\
\text { services among cloud providers and } \\
\text { cloud users. }\end{array}$ \\
\hline Broker & $\begin{array}{l}\text { A body which helps in keeping the track } \\
\text { of performances, delivery and uses of } \\
\text { cloud services. }\end{array}$ \\
\hline
\end{tabular}

Fig 3 elucidates the connections between the actors. A cloud user can appeal for cloud services directly from a cloud provider or indirectly through the help of cloud broker. A cloud auditor performs autonomous audits and can contact the others to gather essential data.

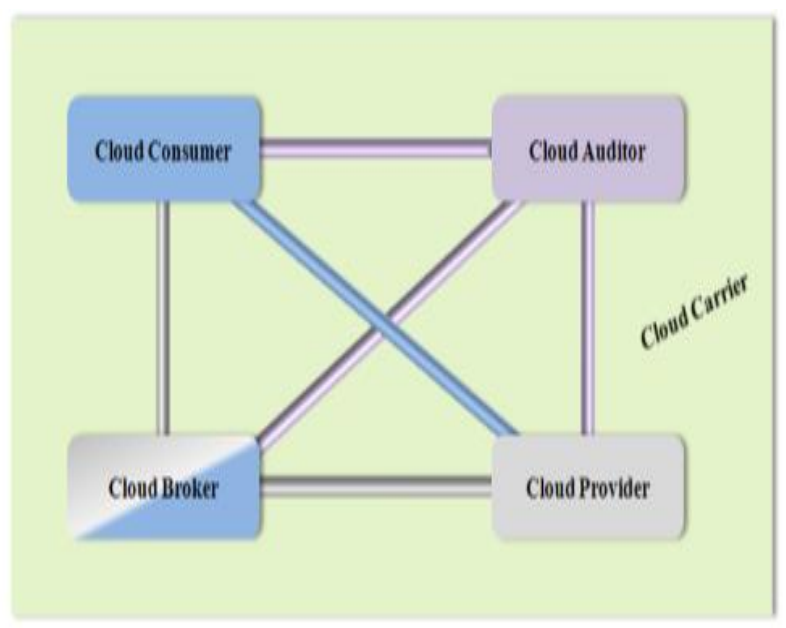

Fig. 3 The connections between the actors

\section{Load Balancing for Cloud Computing}

The main work of load balancing is to remove the burden from the VMs who have been assigned lot of work as compared with others and assign those overloaded work to under loaded VMs. The overall performance of system can be achieved using load balancing. The algorithms used for load balancing are classified in two different types' i.e static load balancing algorithms and dynamic load balancing algorithms
In static load balancing algorithms the judgments linked to balancing of load will be done at compile time when resource necessities are evaluated. This algorithm is very simple and need no extra monitoring.

In dynamic load balancing algorithms changes are made to the sharing of work load between nodes at run time. The literature review of load balancing is discussed below:

Table 2. Literature review of load balancing

\begin{tabular}{|c|c|}
\hline Authors & Description \\
\hline Houle et al. [9] & $\begin{array}{l}\text { Presented algorithms which can be } \\
\text { used for static load balancing on } \\
\text { trees considering that the overall } \\
\text { load is a static one. }\end{array}$ \\
\hline Hu et al. [6] & $\begin{array}{l}\text { Proposed an algorithm called as } \\
\text { optimal data migration using } \\
\text { dynamic load balancing over the } \\
\text { calculation of large range multiplier } \\
\text { of the euclidean form of shifted } \\
\text { weight. These works successfully } \\
\text { help in minimizing the data } \\
\text { program in similar surroundings, } \\
\text { but cases problem in heterogeneous } \\
\text { situations. }\end{array}$ \\
\hline $\begin{array}{l}\text { Genaud et al. } \\
{[12]}\end{array}$ & $\begin{array}{l}\text { Uses the MPI scatterv primeval for } \\
\text { supporting master slave load } \\
\text { balancing by taking into attention } \\
\text { the optimization of calculation and } \\
\text { data circulation via a linear } \\
\text { programming algorithm. Though, } \\
\text { this key is inadequate to static load } \\
\text { balancing. }\end{array}$ \\
\hline $\begin{array}{l}\text { Shiva } \\
\text { Razzaghzadeh } \\
\text { et al. [2] }\end{array}$ & $\begin{array}{l}\text { Presented a new time optimizing } \\
\text { probabilistic load balancing } \\
\text { algorithm in grid computing. This } \\
\text { algorithm takes the resources } \\
\text { constructed over past status and } \\
\text { minimum completion time. The } \\
\text { chief drive of this algorithm is to } \\
\text { create load balancing and decrease } \\
\text { the response time. }\end{array}$ \\
\hline $\begin{array}{l}\text { Wei Zhu et al. } \\
\text { [5] }\end{array}$ & $\begin{array}{l}\text { Presented task load balancing } \\
\text { approaches for grid computing. A } \\
\text { hierarchical load balancing } \\
\text { approach and associated algorithms } \\
\text { built over neighborhood property } \\
\text { are also the part of paper. This } \\
\text { approach gives rights over local } \\
\text { balancing in first. The chief } \\
\text { advantage of this awareness is to cut } \\
\text { the amount of messages switched } \\
\text { between grid resources. }\end{array}$ \\
\hline
\end{tabular}

\section{ENERGY EFFICIENCY OF CLOUD COMPUTING}

Literature review of energy efficiency of cloud 
computing is discussed in the table 3 .

Table 3. Literature review of energy efficiency of cloud computing

\begin{tabular}{|c|c|}
\hline Authors & Description \\
\hline $\begin{array}{l}\text { Ankita } \\
\text { Choudhary } \\
\text { et al. [14] }\end{array}$ & $\begin{array}{l}\text { Stated that energy proficiency is } \\
\text { gradually significant for upcoming ICT } \\
\text { as the amplified usage of ICT, together } \\
\text { with increasing energy costs and the } \\
\text { essential for moderating the } \\
\text { greenhouse gas productions call for } \\
\text { energy efficient technologies that } \\
\text { reduce the overall energy depletion of } \\
\text { calculation, loading and } \\
\text { infrastructures. Cloud computing has } \\
\text { freshly received considerable attention, } \\
\text { as a talented method for conveying ICT } \\
\text { services by cultivating the use of data } \\
\text { center resources. }\end{array}$ \\
\hline $\begin{array}{l}\text { Aarti Singh } \\
\text { et al. [15] }\end{array}$ & $\begin{array}{l}\text { presented that based on a recent data } \\
\text { center energy forecast report, user can } \\
\text { expect that savings of the order of } 22 \% \\
\text { can be attained in server and network } \\
\text { energy consumption with esteem to } \\
\text { current levels and that these savings } \\
\text { may encourage an additional } 31 \% \\
\text { saving in cooling needs as detailed in a } \\
\text { study by HP and the Uptime Institute. }\end{array}$ \\
\hline $\begin{array}{l}\text { Dhinesh } \\
\text { Babu et al } \\
{[18]}\end{array}$ & $\begin{array}{l}\text { States that ICT guzzles a growing } \\
\text { volume of energy, but is also } \\
\text { contributory in growing production and } \\
\text { economic success and in falling energy } \\
\text { outlay from other sources over e-work, } \\
\text { e-commerce and e-learning. Customary } \\
\text { network design has tried to find to } \\
\text { lessen infrastructure costs and } \\
\text { maximize QoS. However, ICT also } \\
\text { shows a complex role in energy } \\
\text { consumption through the communicate } \\
\text { more and travel less pattern, and also } \\
\text { with the use of smart devices in homes } \\
\text { and offices to improve energy } \\
\text { management. }\end{array}$ \\
\hline
\end{tabular}

\section{PROPOSED METHODOLOGY}

Particle swarm algorithm and cuckoo search algorithm are two algorithms which are used and their results are evaluated using simulator CloudSim. These two algorithms are discussed below.

\section{A. Particle swarm algorithm}

In PSO, a group of elements were castoff for demonstrating the possible solutions and comprising of the constant search over best solution. This method moves the elements over $\mathrm{x}, \mathrm{y}$ position with some velocity which is to be calculated in every iteration step. Each element movement has its own influence foe getting the best known position and the space search. The final result obtained using the particle swarm expects in covering of best solution.

It is essential to declare that PSO do not use gradient descent, so PSO can be used to nonlinear problems easily.

The algorithm for PSO is summarized under:

\section{Create and initialize an nx-dimensional swarm;}

repeat

for each particle $i=1, \ldots, n s$ do

//set the personal best position

if $\mathrm{f}(\mathrm{xi})<\mathrm{f}$ (yi) then

yi = xi;

end

//set the global best position if $f\left(y^{i}\right)<f\left(y^{*}\right)$ then

$\mathbf{y}^{\wedge}=\mathbf{y i}$

end

end

for each particle $i=1, \ldots, n$, do

update the velocity using equation (16.2);

update the position using equation (16.1);

end

until stopping condition is true;

\section{B. Cuckoo search algorithm}

Cuckoos are attractive birds, they not only make beautiful sounds, but also because of its violent reproduction approach. Cuckoo search is one of the most used optimization [8] technique. Because it help in providing better results in just minute change done in any parameter. So this search is widely accepted in many fields these days.

CSO algorithm is discussed as below: 


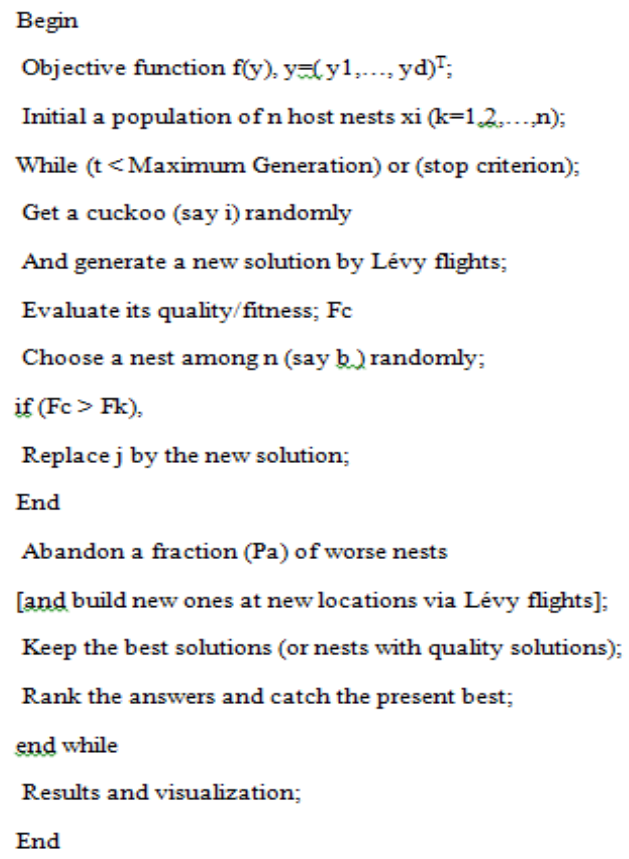

Cuckoo search [10] is constructed over three ideal guidelines

- One egg is laid by each cuckoo. The egg laid is dumped in any random nest.

- For the next generation, the nest, this is having high quality of eggs will be taken further for execution [12].

- The host nests which are accessible are fixed. The host bird help in discovering the laid egg with a probability p_a $(0,1)$.

\section{CloudSim}

CloudSim simulator used for cloud was given by Buyya which take help of all the infrastructure and applications which are presented in a cloud. This approach makes the work easier and more feasible. Cloudsim approach help in checking the feasibility of various events. Cloudsim is simulated by various applications of cloud computing, cloud infrastructures, service brokers, cloud allocation policies and many more. To begin with the simulation process, Cloudsim under goes few important steps.

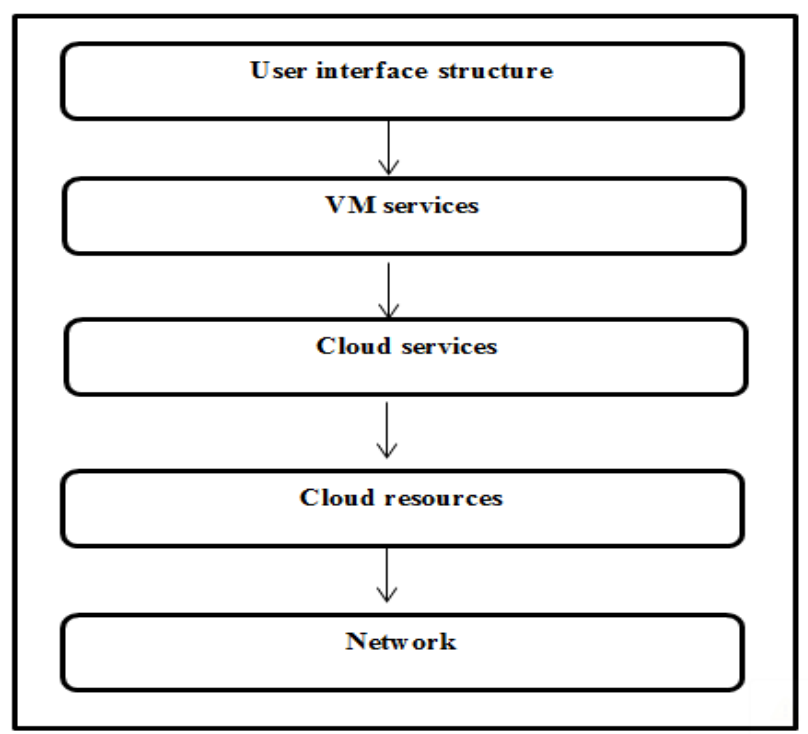

Fig. 4 Cloudsim components
Following are the steps which are followed during the execution of cloudsim:

- Brokers who are proportional to the users are to be selected.

- Variables are to be initialized.

- Cloudsim information service is to be made.

- Cloudlets are to be created. Various parameters for cloudlets are number of jobs, output size, number of PE's used for executing the job, length and size of the file.

- Data center to be created. Data center may include storage size; RAM size, MIPS, Bandwidth and number of PEs etc.

- Broker instances to be created, as they help in communication process.

- Virtual Machines to be created, which include storage size, MIPS, Bandwidth, number of PEs.

- Once VM and cloudlets are created, they are submitted to the broker.

- Start Simulation.

- Stop Simulation, when execution finishes.

\section{A. Simulation results}

Cloudsim and cloud analyst have been cast-off for the results. To estimate and match the presentation of the proposed model basic parameters have been used. Some screenshots of the output of the algorithms are shown below:

- For load balancing such as Selection of VMs, Execution Time, etc.

- For Energy Consumption such as Energy Consumption, Utilization, etc.

- For Resource Migrations such as Response Time, Migration Time, etc.

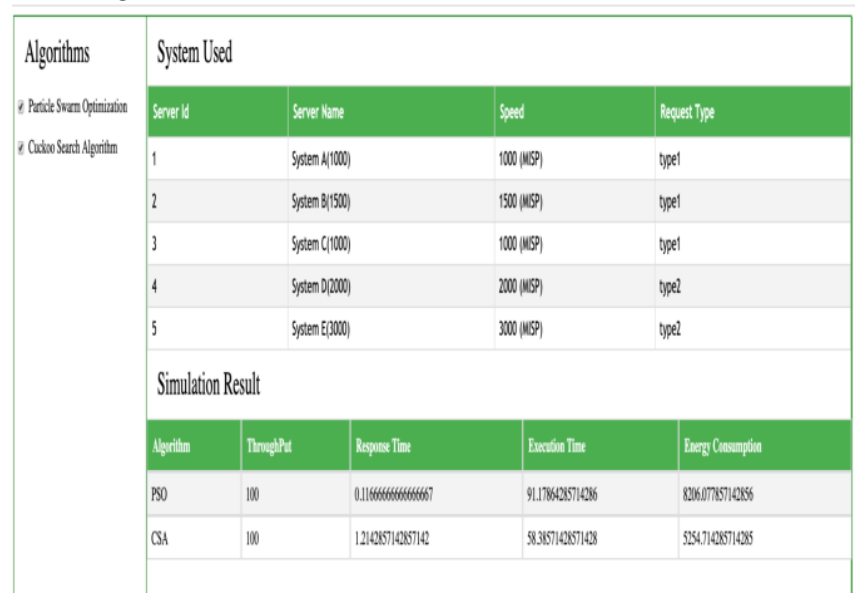

Fig. 5 Output 1 of PSO and CSA

Fig. 5 shows the screenshots of algorithms named as PSO and CSA. These are implemented in the simulator called Cloudsim. Output has been shown in the form Throughput, Response time, execution time and energy consumption. Outputs of these two algorithms vary according to the no of jobs. So this screenshot provides results when total no of jobs are 5

Published By: 




Fig. 6 Output 2 of PSO and CSA

In Fig. 6 Outputs of these two algorithms vary according to the no of jobs. So this screenshot provides results when total no of jobs are 5 . It shows the screenshots of algorithms named as PSO and CSA. These are implemented in the simulator called Cloudsim. Output has been shown in the form Throughput, Response time, execution time and energy consumption.

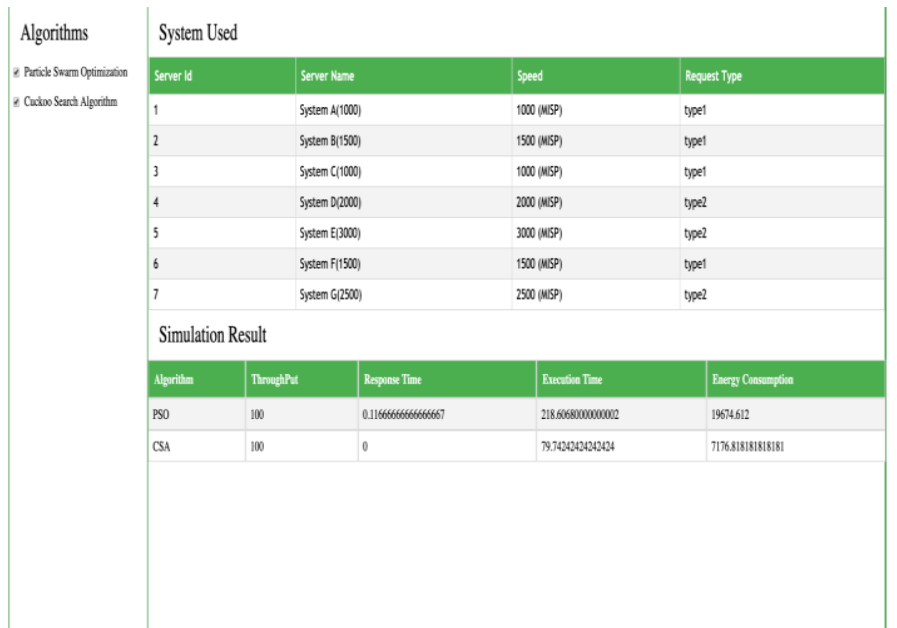

Fig. 7 Output 3 of PSO and CSA

In Fig. 7 output has been shown in the form Throughput, Response time, execution time and energy consumption. It shows the screenshots of algorithms named as PSO and CSA. These are implemented in the simulator called Cloudsim. Outputs of these two algorithms vary according to the no of jobs. So this screenshot provides results when total no of jobs are 7



Fig. 8 Output 4 of PSO and CSA

Figure 8 also shows the screenshots of algorithms named as PSO and CSA. This screenshot provides results when total no of jobs are 8 . These are implemented in the simulator called Cloudsim. Output has been shown in the form Throughput, Response time, execution time and energy consumption. Outputs of these two algorithms vary according to the no of jobs.

\section{B. Output tables and graphs:}

The results of both approaches are shown in the form of the graphs. Two tables are created with parameters like response time, execution time, Energy consumption.

Table 4. Simulation results for PSO Algorithm for different number of jobs.

\begin{tabular}{|c|c|c|c|c|}
\hline \multirow[b]{2}{*}{$\begin{array}{c}\text { No. } \\
\text { of } \\
\text { Jobs }\end{array}$} & \multicolumn{4}{|c|}{ Parameters Name } \\
\hline & $\begin{array}{l}\text { Throu } \\
\text { ghput }\end{array}$ & $\begin{array}{c}\text { Response } \\
\text { Time }\end{array}$ & $\begin{array}{c}\text { Execution } \\
\text { Time }\end{array}$ & $\begin{array}{c}\text { Energy } \\
\text { Consumption }\end{array}$ \\
\hline 5 & 100 & 0.116 & 91.178 & 8206.077 \\
\hline 6 & 100 & 0.116 & 121.519 & 10936.782 \\
\hline 7 & 100 & 0.116 & 218.606 & 19674.612 \\
\hline 8 & 100 & 0.116 & 248.390 & 22355.146 \\
\hline
\end{tabular}

Table 4 shows the output of PSO algorithm in different no of jobs.

Various parameters are shown in this tabes, These are response time, execution time, energy consumption. Total no of jobs are 5,6,7,8 in this table.

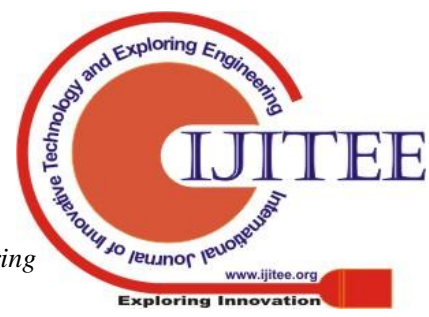


Table 5. Simulation results for CSA Algorithm for different number of jobs.

\begin{tabular}{|c|c|c|c|c|}
\hline \multirow{2}{*}{$\begin{array}{c}\text { No. } \\
\text { of } \\
\text { Jobs }\end{array}$} & \multicolumn{4}{|c|}{ Parameters Name } \\
\cline { 2 - 5 } & $\begin{array}{c}\text { Through } \\
\text { put }\end{array}$ & $\begin{array}{c}\text { Respons } \\
\text { e Time }\end{array}$ & $\begin{array}{c}\text { Execution } \\
\text { Time }\end{array}$ & $\begin{array}{c}\text { Energy } \\
\text { Consumption }\end{array}$ \\
\hline 5 & 100 & 1.214 & 58.385 & 5254.714 \\
\hline 6 & 100 & 0.857 & 120.599 & 10854 \\
\hline 7 & 100 & 0 & 79.742 & 7176.818 \\
\hline 8 & 100 & 0 & 94.405 & 8496.522 \\
\hline
\end{tabular}

Table 5 shows the output of CSA algorithm in different no of jobs. Various parameters are shown in this tabes, These are response time, execution time, energy consumption. Total no of jobs are 5,6,7,8 in this table.

\section{Response time for PSO and CSA algorithm in different jobs:}

The difference among the considerations of these algorithms is given below. The enactment of these algorithms has been evaluated in different environments. The Author has already discussed the configurations of virtual machine and cloudlets. So to get better results author has tested various algorithms in different number of jobs. The results of these algorithms are presented in the form of graphs. All the results are implemented in simulation kit named as Cloudsim. Figures shown below give the comparison of two algorithms by taking multiple jobs. Table 4 and 5 has been shown the performance comparison of algorithms with different parameters.

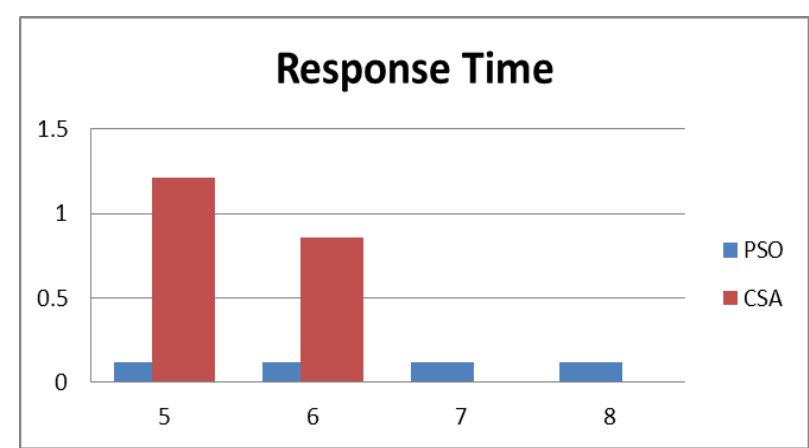

Fig. 9 Response time for PSO and CSA algorithm

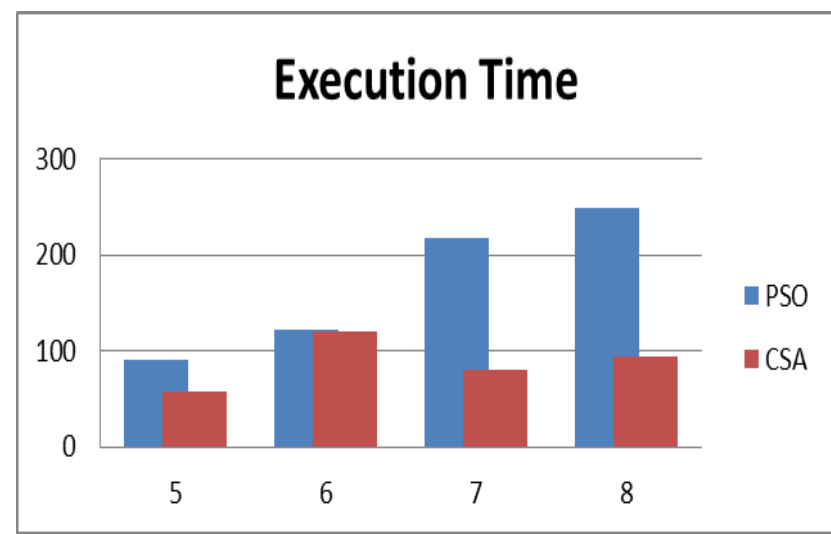

The comparisons of both algorithms have been done with the help of simulator. This graph shows the response time of both algorithms. In this scenario algorithm worked on different jobs.

When no of jobs $=5$, Response time of $\mathrm{CSA}=1.214$, $\mathrm{PSO}=0.116$, No of jobs $=6$, Response time of $\mathrm{CSA}=120.599$, $\mathrm{PSO}=0.116$ (remain same), No of jobs $=7$, Response time of $\mathrm{CSA}=0, \mathrm{PSO}=0.116$, No of jobs $=8$, Response time of $\mathrm{CSA}=$ $0, \mathrm{PSO}=0.116$

Fig. 10 Execution time for PSO and CSA algorithm in different jobs

This graph shows the Execution time of both algorithms. In this scenario algorithm worked on different jobs. When no of jobs $=5$, execution time of $\mathrm{CSA}=58.385, \mathrm{PSO}=91.178$

No of jobs $=6$, execution time of $\mathrm{CSA}=120.599$, $\mathrm{PSO}=121.519$, No of jobs $=7$, execution time of $\mathrm{CSA}=$ 79.742 , $\mathrm{PSO}=218.606$, No of jobs $=8$, execution time of $\mathrm{CSA}=94.405, \mathrm{PSO}=248.390$

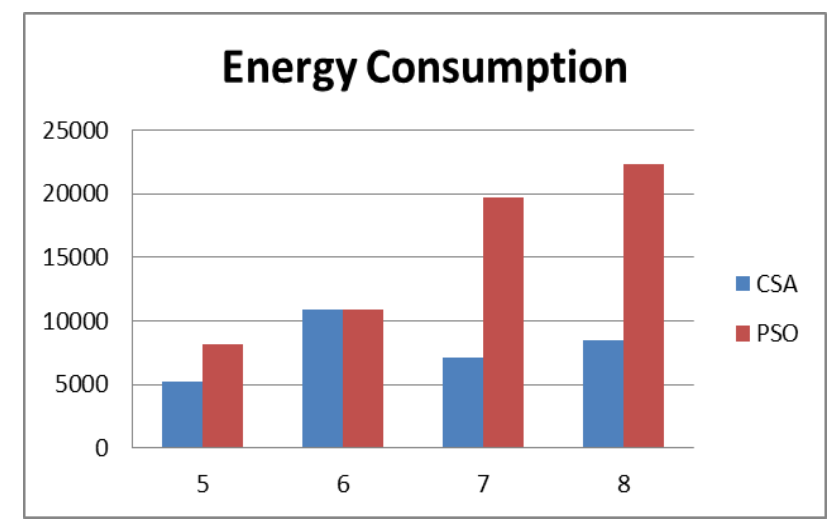

Fig. 11 Energy consumption for PSO and CSA algorithm in different jobs

This graph shows the Execution time of both algorithms. In this scenario algorithm worked on different jobs. When no of jobs $=5$, Energy consumption of $\mathrm{CSA}=5254.714$, $\mathrm{PSO}=8206.077$, No of jobs=6, Energy consumption of CSA= 10854, $\mathrm{PSO}=10936.782$, No of jobs=7, Energy consumption of $\mathrm{CSA}=7176.818, \mathrm{PSO}=19674.612$, No of jobs= 8, Energy consumption of $\mathrm{CSA}=8496.522, \mathrm{PSO}=22355.146$

\section{CONCLUSION}

In the last few years existence of cloud computing has replaced the landscape of Information technology. It has been envisioned that cloud computing will be provided as 5th utility that will contribute the fundamental computing services. Cloud computing provides a collection of resources that can access anywhere by using internet. Cloud Computing has Major Characteristics like elasticity, on-demand self-service, etc. that play important role in provisioning and releasing the services. It offers numerous service models and deployment models. In this paper various Cloud Computing and load

Published By:




balancing are also discussed. Though some difficulties exist in Cloud computing and to handle load balancing is one of them. A Technique that distributes the huge dynamic local workload across all the Nodes is called as load balancing. In this paper literature review of load balancing are also discussed. Two algorithm named as PSO and CSA are discussed and their results and comparison have been shown using simulator CloudSim. Different parameters such as Execution Time, Energy Consumption, Utilization, Response Time, Migration Time, etc.are used. In future work Proposed Hybrid Energy efficient model will be implemented and Cloudsim simulator for cloud computing will be used to show all the results of the proposed technique.

\section{REFERENCES}

[1] Vanitha, P. Marikkannu (2017).Effective resource utilization in cloud environment through a dynamic well-organized load balancing algorithm for virtual machines. Elsevier Ltd.

[2] Shiva Razzaghzadeh, Ahmad Habibizad Navin, Amir Masoud Rahmani, Mehdi Hosseinzadeh. (2017). Probabilistic modeling to achieve load balancing in Expert Clouds. ElsevierB.V.

[3]Mohammad Goudarzi, Mehran Zamani, Abolfazl Toroghi Haghighat.(2017). A fast hybrid multi-site computation offloading for mobile cloud computing. Journal of Network and Computer Applications, Elsevier.

[4]Muhammad Baqer Mollah, Md. Abul Kalam Azad, Athanasios Vasilakos.(2017).Security and privacy challenges in mobile cloud computing: Survey and way Ahead. Journal of Network and Computer Applications, Elsevier.

[5] Sungju Huh , Seongsoo Hong. (2017). Providing fair-share scheduling on multicore computing systems via progress balancing. The Journal of Systems and Software, Elsevier.

[6] Hassan Raei, Nasser Yazdani. (2017). Performability analysis of cloudlet in mobile cloud computing. Information Sciences, Elsevier.

[7]Piotr Nawrocki, Wojciech Reszelewski. (2017).Resource usage optimization in Mobile Cloud Computing. Computer Communications, Elsevier.

[8]Wei Zhu, Yi Zhuang, Long Zhang. (2017). A three-dimensional virtual resource scheduling method for energy saving in cloud computing. Future Generation Computer Systems, Elsevier.

[9]SONG Ningning, GONG Chao, AN Xingshuo, ZHAN Qiang. (2016). Fog Computing Dynamic Load Balancing Mechanism Based on Graph Repartitioning. China Communications.

[10] Lei Zhang, Jiangchuan Liu, Edith Cheuk-Han Ngai, Wenwu Zhu.(2016). On Energy-Efficient Offloading in Mobile Cloud for RealTime Video Applications. IEEE.

[11] Mohammad Mehedi Hassan, Majed Alrubaian, Atif Alamri. (2016). Effective QoS aware Novel Resource Allocation Model for Body Sensor-Integrated Cloud platform. ICACT.

[12] Qi Liu, Weidong Cai, Jian Shen, Dandan Jin, Nigel Linge. (2016). A Load Balancing Approach B ased on Modified K-ELM and NSGA-II in a Heterogeneous Cloud Environment. IEEE International Conference on Consumer Electronics.

[13] Deepak KumarPatel, DevashreeTripathy, C.R.Tripathy. (2016). Survey of load balancing techniques for Grid. Journal of Network and Computer Applications, Elsevier.

[14] Ankita Choudhary,Shilpa Rana, K.J. Matahai. (2016). A Critical Analysis of Energy Efficient Virtual Machine Placement Techniques and its Optimization in a Cloud Computing Environment. International Conference on Information Security \& Privacy, Elsevier.

[15] Aarti Singh, Dimple Juneja, Manisha Malhotra. (2015). Autonomous Agent Based Load Balancing Algorithm in Cloud Computing. ICACTA, Elsevier.

[16] Ebin Deni Raj and Dhinesh Babu L.D. (2015). A Two Pass Scheduling Policy based Resource allocation for MapReduce. ICICT, Elsevier.

[17] Fatemeh Jalali, Kerry Hinton, Robert Ayre, Tansu Alpcan, and Rodney S. Tucker. (2014). Fog Computing May Help to Save Energy in Cloud Computing. IEEE Journal.

\section{AUTHORS PROFILE}

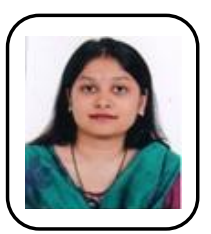

Shanky Goyal, presently is a research scholar in Department of Computer Science IKGPTU, Kapurthala, Punjab. She is also working as Assistant Professor in Chandigarh Engineering College, Landran.

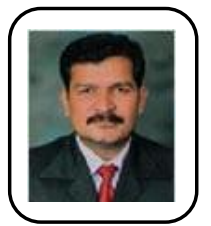

Dr. Shashi Bhushan did his Ph.D from NIT, Kurukshetra, India in 2015. Dr. Bhushan is presently working as a HOD and professor in department of Computer Science and Engineering at CEC, Landran since April 2011. He is having more than 18 years of academic and administrative experience. His areas of interest are Peer to Peer Networks, Mobile Computing and Databases. 